\title{
RELIGIOSIDADE, EDUCAÇÃO JESUÍTICA E AS CASAS DE BÊ-Á-BÁ NO BRASIL COLONIAL
}

\section{RELIGIOSITY, JESUITIC EDUCATION AND THE HOUSES OF BÊ-Á- BÁ IN COLONIAL BRAZIL}

\author{
Andreza da Silva Vieira ${ }^{33}$ \\ Natália Cristina de Oliveira ${ }^{34}$ \\ David Antonio de Castro Netto ${ }^{35}$
}

\begin{abstract}
Resumo: Este artigo tem como objetivo analisar a educação dos gentios em terras brasílicas, valendo-se do princípio de que os jesuítas foram os precursores dessa formação e trouxeram com eles nas embarcações suas ideologias, princípios, valores e religiosidade. As Casas de Bê-á-bá expressaram a possibilidade de colonizar as regiões e instituir os ideais religiosos dos lusitanos aos gentios. Utilizamos referenciais bibliográficos e fontes que deram condições de compreender desdobramentos educativos religiosos na América Portuguesa. Com o ensino das Casas educativas sistematizava-se maior possibilidade de se propagar a religiosidade católica aos nativos, do que pelos próprios clérigos - aquém da cultura e configuração social do Novo Mundo.
\end{abstract}

Palavras-chave: Educação Jesuítica; Brasil colônia; Casas de Bê-á-bá

Abstract: This article aims to analyze the education of the Gentiles in Brazilian lands, using the principle that the Jesuits were the precursors of this formation and brought with them in the boats their ideologies, principles, values and religiosity. Casas de Bê-á-bá expressed the possibility of colonizing the regions and instituting the religious ideals of the Lusitanians to the Gentiles. We used bibliographical references and sources that gave the conditions to understand religious educational developments in Portuguese America. With the teaching of the educational houses, it was possible to propagate Catholic religiosity to the natives rather than to the clerics themselves, short of the culture and social configuration of the New World.

Keywords: Jesuit Education; Brazil colony; Casas de Bê-á-bá

\footnotetext{
${ }^{33}$ Mestre em História pela Universidade Estadual de Maringá. Professora da Rede Básica de Ensino. E-mail: deza.vieira@live.com.

${ }^{34}$ Doutora em Educação pela Universidade Estadual de Ponta Grossa. Docente do curso de Pedagogia da Universidade Federal do Mato Grosso do Sul. E-mail: natdeoliveir@gmail.com.

${ }^{35}$ Doutor em História pela Universidade Federal do Paraná. Docente do curso de História da Universidade Estadual de Maringá. E-mail: david.acnetto@gmail.com.
}

REHR | Dourados, MS | v. 13 | n. 25 | p. 35-54 | Jan. / Jun. 2019 


\section{HISTÓRIA \\ MUNDO LUSO BRASILEIRO: RELAÇÕES DE PODER E RELIGIÃO}

Introdução

O objetivo deste artigo é analisar, com base no método pedagógico da Ordem Companhia de Jesus, de que forma os religiosos desempenharam os princípios de ensino nas Casas de Bê-á-bá da colônia brasílica. A origem dessas Casas estava ligada ao processo de conversão dos gentios, sobretudo índios e mamelucos. Sendo assim, embora a preocupação das Casas não fossem como a de um Colégio, apresentavam características relacionadas aos mesmos. Para que seja possível este entendimento, antes, nos debruçamos sobre algumas considerações sobre o método pedagógico estruturado por esses padres.

Partimos do pressuposto que aquele que pesquisa, mesmo que subjetivamente, escolhe conceitos e estruturas que farão parte de sua análise; por meio da formulação da narrativa historiográfica é possível esclarecer relações e fatos, mas para isso é necessário considerar que "[...] todo conceito é não apenas efetivo enquanto fenômeno linguístico; ele é também imediatamente indicativo de algo que se situa para além da língua" (KOSELLECK, 1992, p. 136). Portanto, cabe ao narrador a detenção de sua prática, significando não se ater totalmente às definições e também não as ignorar, pois serão como norte à pesquisa histórica.

Estudar períodos distantes daquele que o pesquisador vive requer cuidado e atenção. Faz-se necessário analisar a maior quantidade de pontos de vista possíveis, além de não se deixar levar por ideias e sentimentos inculcados em sua própria época. Por isso, a ideia de significações - antes de mais nada - tem preceitos nas representações; a definição de um processo pode ser diferente dependendo da cultura, de onde o ser social está localizado e até mesmo dentro de seu espaço temporal (PAIVA, 2012).

O meio social da sociedade europeia ocidental, do século XVI, apresentava outros preceitos e definições que eram considerados válidos ao bom funcionamento e convívio dos indivíduos. A partir das mais diversas análises feitas por pesquisadores, e por meio de documentos deixados pelos contemporâneos do século $\mathrm{XVI}$, visualizamos uma sociedade onde a religião era prioridade na vida dos 


\section{HISTÓRIA}

\section{MUNDO LUSO BRASILEIRO: RELAÇÕES DE PODER E RELIGIÃO}

sujeitos. É possível afirmar que naquela conjuntura os dogmas religiosos davam sustentação ao formato de vida daquela sociedade. A vivência religiosa "[...] na época não era algo adjacente à vida social do indivíduo como o é nos dias de hoje. Ela era a vida social dos moradores, tanto que o cotidiano era articulado com base nas imposições clericais" (PAIVA, 2012, p. 24).

Para apresentar a discussão suscitada, este artigo está organizado em dois momentos. No primeiro, contemplamos assuntos referentes à educação, sobretudo, desenvolvida pelos padres inacianos: princípios da pedagogia jesuítica relacionados à quarta parte das Constituições da Companhia de Jesus, de 1556; questões referentes ao Ratio Atque Institutio Studiorum Societatis lesu, de 1599; e alguns dos princípios inacianos. E, por fim, abordamos questões referentes às Casas de Bê-ábá que auxiliaram no processo de "instrução" e catequização dos gentios.

Poder e princípios educativos da Companhia de Jesus

Durante, pelo menos, seis séculos apenas parte da nobreza e clero tinham acesso ao saber que significou o estudo bíblico, gramatical e celebração da liturgia. Esse controle do saber foi proeminente na Europa até meados do século XVIII. Carlo Ginzburg (1989) relata grande ofensiva da burguesia, nos aspectos culturais, que se apropriou de grande parte do saber e o difundiu. Essa difusão também foi controlada: a maior parte da população permaneceu sem acesso à educação. No entanto, a partir desse momento a burguesia também passa a participar da formação e compreensão do conhecimento.

Clérigos renomados da história europeia posicionavam-se contra a busca, popular, pelo saber. Santo Agostinho, por exemplo, afirmou que a curiosidade vã era doença fatal da sociedade. As perguntas acerca do universo, constelações e planetas estiveram sempre presentes no imaginário social, que questionavam mesmo indiretamente - o saber bíblico (PAIVA, 2012).

O período renascentista, quando comparado aos séculos anteriores, pode ser considerado como tolerante para com os pesquisadores e todos aqueles que duvidavam do senso comum. Os anos que precederam o Renascimento foram 


\section{HISTÓRIA}

\section{MUNDO LUSO BRASILEIRO: RELAÇÕES DE PODER E RELIGIÃO}

"prejudiciais a ciência", pois para o clero, grupo pertencente ao topo da pirâmide social, as respostas de todas as coisas estavam nas Escrituras Sagradas; não havia motivo para procurar em outros lugares. Aqueles que ousavam divulgá-lo era porque não acreditavam na Bíblia, e consequentemente deveriam ser punidos.

$\mathrm{O}$ século $\mathrm{XVI}$, neste sentido, trouxe abertura e certa tolerância à efervescência intelectual, ainda que para alguns segmentos da Igreja 0 conhecimento fosse classificado como inútil. As dúvidas fizeram a sociedade deixar de lado (não totalmente) o autoritarismo que nela era imposta, em busca do bem comum: respostas práticas. Difícil esquecer a quantidade de mortes causadas pela desconexão entre as escrituras sagradas e a cientificidade. Neste momento, "[...] tudo é colocado em dúvida; talvez tenha sido este o sentido do Renascimento, época das audácias. O homem não tem mais o que o dirija; talvez essa tenha sido a revolução" (WOORTMANN, 1997, p. 29).

Enquanto determinados setores eclesiásticos repudiavam a ideia de conhecimento vindo da ciência outros apoiavam as pesquisas, inclusive financeiramente. Procurar respostas, além-bíblico, não deveria ser algo condenado pela Igreja, e foi o que diversos clérigos criticaram ao dizer que o saber deveria estar ao alcance da sociedade. Procurar respostas não era duvidar de Deus, mas apenas analisar a criação cristã de modo prático e científico. Neste sentido, é válida a observação de que o período do Renascimento abriu frestas no forte que separava o conhecimento e as pessoas (PAIVA, 2012).

O processo de "busca pelo conhecimento" foi aberto, ainda, a um número restrito de pessoas dentro de certa classe social. A problemática se encontrava em entender que os questionamentos não faziam o pesquisador menos crédulo ao cristianismo, mas que muitos aproveitaram da nova onda intelectual para expor o que sob circunstâncias normais não falariam, como o fato de não acreditar na Igreja e em seus dogmas.

A concepção de ciência na historiografia, por muito tempo, foi vista como heterogênea em relação ao conceito de religião. Por terem visões distintas acerca de determinados assuntos, e somados ao fato do controle moral da lgreja no século $\mathrm{XVI}$, não se via possibilidade da junção desses dois temas. Entretanto, Klaas Woortmann (1997) defende que a ciência foi oriunda de espaços eclesiásticos. 


\section{HISTÓRIA \\ MUNDO LUSO BRASILEIRO: RELAÇÕES DE PODER E RELIGIÃO}

Inicialmente não fora radical e expansiva como apresenta-se na contemporaneidade. Houve um tímido, e depois crescente, incentivo às pesquisas. Esse estímulo se justificava sob forma de comprovação dupla às escrituras sagradas: Deus já havia provado e os pesquisadores trariam uma nova afirmação dentro de seus próprios estudos.

A ciência era cultivada em benefício da humanidade, mas sobretudo de Deus. Em meio a expansão marítima e o encontro entre povos distintos surge uma necessidade sintomática de reformular as respostas a diversas questões. Algumas certezas, antes aceitas, foram sendo cada vez mais questionadas em razão às vivências, as relações e experiências que o próprio ser social passa a questionar. Desta maneira, é possível observarmos que não houve conciliação entre o ensino da Igreja e o novo saber, mas isto não pode significar que houve ruptura total entre eles.

A Igreja pertencia a um lugar de grande destaque na sociedade, e fazia uso de seu poder para a propagação da fé cristã e sua adoção por parte dos novos fiéis. Os séculos XV e XVI foram marcados por mudanças em aspectos morais, no sentido da propagação de críticas aos ideais de fé. É importante lembrar que, em toda Europa, a Igreja encarava uma forte e dogmática resistência da Reforma Protestante, pois a mesma monopolizava os conceitos religiosos, condenando aqueles que iam contra seus costumes cristãos e preservando a supremacia. Peter Johan Mainka (2012) assevera que a Reforma quebrou a união da cristandade ocidental, fundamentados pela Renascença e pelo Humanismo.

É neste ponto que abordamos a Companhia de Jesus nas práticas sociais, culturais, religiosas e educativas da conjuntura em questão. Entendemos ser recorrente e habitual considerar, na história e historiografia, que a educação na modernidade passou pela ação da Companhia de Jesus - tanto nos domínios portugueses, quanto no da colônia brasileira; isto porque dois aspectos explicam superficialmente, ao menos nas primeiras décadas de existência, a atuação desta Ordem religiosa:

[...] o fundamento teológico e filosófico da escolástica como o elemento conservador, e o enfrentamento de inéditas experiências ligadas ao processo de expansão da sociedade ocidental como o elemento novo, como o desconhecido e moderno de sua atuação. Os 


\section{HISTÓRIA}

\section{MUNDO LUSO BRASILEIRO: RELAÇÕES DE PODER E RELIGIÃO}

jesuítas assumiram, com o tempo, esses dois fundamentos como essenciais para a atuação em seus diversos meios, principalmente os relacionados ao Império português do século XVI (COSTA, 2004, p. 120).

A ação educacional não apresentava-se, a priori, como objetivo da Ordem fundada por Inácio de Loyola, mas passou posteriormente a norteá-la. A educação jesuítica possui características próprias do contexto de sua origem. Os cuidados iniciais com as questões educativas tiveram origem na IV parte das Constituições Jesuítica (1997), documento inicialmente escrito por Inácio de Loyola. Direcionavase à Ordem princípios e normas para sua estruturação, instituía que a mesma não fosse composta por monges ou frades, mas sim clérigos: Religio Clericorum Societatis lesu (assim foi denominada no Concílio de Trento), porém, também possuía permissão para admitir fiéis que não se tornassem clérigos, ficando como irmãos coadjutores.

Nas Constituições, o código apresentava-se de forma nítida - no que diz respeito aos objetivos da Companhia. Seu propósito maior não era o de cultivar apenas a conversão, mas sim auxiliar nas almas que os circundavam a fim de alcançar a salvação e a perfeição religiosa do próximo. Para ingressas na Ordem, dever-se-ia realizar três votos: obediência, pobreza e castidade. Para ilustrar esse gesto não se poderia ter rendas financeiras, nem manter nenhum tipo de contato ou vínculo com dinheiro, apenas aqueles que eram - excepcionalmente - autorizados a isso (CONSTITUIÇÕES, 1997).

As Constituições, por ser o documento base da Ordem religiosa, apresentavase com um número extenso de informações - pois tratavam de assuntos gerais. Sendo assim, em 1599, a educação inaciana ganha um documento e um método próprio, regular e orientado que fica conhecido como Ratio Atque Institutio Studiorum Societatis lesu. Embora sua publicação tenha sido após a data de fundação dos primeiros colégios administrados pelos padres, os métodos propostos já haviam sido materializado no plano das escolas jesuíticas.

Em muitos casos os colégios da Companhia em Portugal, e depois no Brasil, iam além de casas de estudos, serviam também de moradia de seus mestres e colaboradores. Centralizavam na instituição integrantes da organização e da administração da Ordem. Justamente devido a expansão da Ordem inaciana, diga- 


\section{HISTÓRIA \\ MUNDO LUSO BRASILEIRO: RELAÇÕES DE PODER E RELIGIÃO}

se de passagem vertiginosa, foi necessário instituir normas a fim de organizar e uniformizar as práticas pedagógicas nos colégios. Foram eleitos comissários gerais para realizar instruções e nortear os princípios dos colégios bem como do ensino ministrado nos mesmos. Esses integrantes discutiam legislações e códigos que acentuassem a necessidade de dar e receber orientações para as atividades da Ordem.

Franca (1952), relata que embora a publicação oficial do Ratio Studiorum tenha sido em 1599, no ano de 1586 uma primeira edição foi publicada e, mesmo antes disso, documentos sistemáticos já norteavam as práticas jesuíticas nos colégios - ainda que não estivessem organizados de forma compilada. Os membros da Companhia cortaram repetições e agruparam informações divergentes. A primeira edição do Ratio apresentava 400 páginas, em contrapartida a última contava com 208. Seu volume diminuiu à medida que se descartava o número de regras que, de 837, apresentava-se com 467.

O Ratio não é um tratado de pedagogia, não expõe sistemas nem discute princípios. A edição de 1586 enveredara por este rumo; foi criticada e substituída pela de 1599. Ao tratado sucedeu o programa. Já vimos as razões de ordem prática que ditaram essa mudança de orientação. Outras há, de caráter histórico, que não devem ser esquecidas. Sobre os fins e ideais educativos discutia-se menos no século $X V I$ do que no século $X X$. A unanimidade era então quase perfeita. Os nacionalismos ainda não se haviam ouriçado uns contra os outros nem os estados se esforçavam por converter a educação das massas em instrumento político. $O$ alvo então visado era universal, a formação do homem perfeito, do bom cristão. Não se mirava, com a ação das escolas, dar a consciência de cidadão de tal ou tal império ou de representante desta ou daquela raça predestinadas. Os professores do Renascimento percorriam a Europa sem se sentir estrangeiro em nenhuma parte. Suaréz ensinou em Coimbra, Salamanca e Roma. Vives, espanhol, acha-se bem em Bruges e em Lovaina. Canísio, holandês, passava do Colégio de Messina à Universidade de Ingolstadt (FRANCA, 1952, p. 24).

Além das práticas pedagógicas e elementos fundamentais dos conteúdos a serem ensinados e aprendidos, o documento se referia a aspectos como: administração, currículo e metodologias de ensino. Essas normas deveriam ser respeitadas e seguidas, rigorosamente, pelos professores que compunham as aulas 


\section{HISTÓRIA \\ MUNDO LUSO BRASILEIRO: RELAÇÕES DE PODER E RELIGIÃO}

ministradas nos colégios. Os lentes eram eixos centrais e serviam como referência ao método pedagógico inaciano; como expõe Rodrigues (1917, p. 89):

O ideal que se propôs S. Inácio é sublime, o systema de instrução pareceu-nos solido e bem ordenado, os meios pedagógicos são abundantes, fáceis e apropriados. Como empregar estes meios, como realizar o systema para attingir o ideal? "Tudo depende do professor" [...]. Se o professor sabe, se tem methodo, se possue as qualidades moraes e pedagógicas necessárias ao elevado ministério que desempenha, poderá fazer maravilhas ainda nos talentos medianos; se Ihe escasseiam aquelles dotes, inutilizará talvez os maiores engenhos.

Tanto Rodrigues (1917) quanto Franca (1952) preconizam a importância da formação dos professores que ministravam àquele ensino, assim como é possível conferir nas Constituições Jesuíticas (1997). Ambos os autores corroboram que a vida religiosa seria fundamental para o bom desenvolvimento e formação dos jovens confiados à educação; costumes cristãos embasavam fundamentalmente o desenvolvimento humano, o serviço comunitário e o amor a Deus. Nesse sentido, o professor deveria dar o exemplo a seus alunos.

Não bastam porém lições de palavra pra a formação; é preciso acostumar os jovens desde os primeiros annos ao exercício de boas obras. S. Ignacio nas Constituições, o Ratio Studiorum e os estatutos particulares das universidades e collegios determinaram practicas piedosas que fomentassem o bom espírito dos alumnos. A aula começava por uma pequenina oração que todos, mestre e discípulos, haviam de recitar de joelhos e com a cabeça descoberta (RODRIGUES, 1917, p. 21).

Para ser professor, nos colégios da Companhia, era necessário que fosse demonstrado domínio de todo o conteúdo, que iria dos mais básicos em Humanidades até aos de Filosofia e Teologia. Compreender os princípios das Constituições e do Ratio tornava-se fundamental, pois o domínio do método era indispensável ao ensino e ao estudo.

De acordo com Rodrigues (1917), o Ratio Studiorum e suas leis tornavam a educação jesuítica uma família, suave em suas leis. Os alunos aprendiam mais com as falas dos mestres do que com os ditados. A Companhia sempre esteve comprometida e atenta com o compromisso que Loyola instituiu ao papel do 


\section{HISTÓRIA \\ MUNDO LUSO BRASILEIRO: RELAÇÕES DE PODER E RELIGIÃO}

professor. Indicava-se a importância que o mestre fosse erudito e fizesse parte daquela instituição religiosa.

Para Inácio um educador deveria ser, a princípio, necessariamente, um psicólogo. Havia de ser para todos elles um exemplo constante de virtude que os attrahisse e guiasse docemente para a piedade, havia de ser cuidadoso e perseverante na preparação das aulas, zeloso do adeantamento dos discípulos, igual para todos sem preferências affectuosas, não desprezador de ninguém, mas amigo e protector dedicado de pobres e ricos sem distincção [...] (RODRIGUES, 1917, p. 95).

O Ratio Studiorum norteou, de forma exclusiva, o método pedagógico dos jesuítas até o século XIX. Em 1832 houve mudanças e amplitude no sistema, mas o espírito era sempre o mesmo. Esse documento consistiu na formação de caminhos para o ensino; fossem em aulas, repetições, disputas, academias ou rotina das aulas (PAIVA, 2012). Tanto os Exercícios Espirituais, quanto o Ratio, compuseram a base do desenvolvimento da pedagogia inaciana.

Em meio a este contexto de estruturação dos princípios educativos, sendo firmemente implantados, outras situações conflituosas eram geradas devido a transformação de uma nova fase social, cultural, política e econômica. A resposta da Igreja era sempre tentar rebater às adversidades criando métodos de fortalecimento de seus dogmas, tais como a Companhia de Jesus e a Inquisição Moderna.

A insistência em legitimar o direito divino dos reis, os métodos inquisitórios e a própria criação da Companhia de Jesus foram meios encontrados que permitiram à Igreja se manter no poder ao lado do Estado, mesmo a despeito das referidas mudanças. No mesmo ritmo em que a Europa expandia seus mercados, os jesuítas ampliavam a participação nas decisões da Igreja e mostravam-se cada vez mais envolvidos com o trabalho educativo (CASIMIRO \& SILVEIRA, 2012).

A expansão marítima portuguesa, iniciada no final do século $\mathrm{XV}$, trouxe novas realidades que não foram previstas no plano de ação prático da Coroa. O objetivo foi buscar respostas imediatas às necessidades econômicas comerciais, e investimentos postos nas navegações. Partindo deste pressuposto, a Coroa Portuguesa criou e planejou metas para alcançar o tão sonhado lucro intensivo. As terras "recebidas" por meio do Tratado de Tordesilhas (1494) ficaram conhecidas 


\section{HISTÓRIA \\ MUNDO LUSO BRASILEIRO: RELAÇÕES DE PODER E RELIGIÃO}

como América Portuguesa. Para facilitar a administração colonial, a Coroa lusitana dividiu a região em capitanias, das quais foram dirigidas a homens de confiança do Rei.

Em 7 de janeiro de 1549, Tomé de Souza foi declarado governador geral das terras portuguesas na América, já que o sistema de capitanias hereditárias não estava funcionando de forma efetiva. A justificativa da extinção desse método se dava devido as altas exigências, falta de condições financeiras, de fiscalização e principalmente de abandono as terras partilhadas. O governador geral tinha como objetivo organizar o território, coordenar a colonização, e fortalecer as capitanias contra as resistências indígenas. Além disso, a instalação do governo geral foi acompanhada pela consolidação das estruturas eclesiásticas. O governo, por sua vez, procurou estabelecer relações "pacíficas" com os índios, tanto por razões econômicas quanto pela própria sobrevivência dos europeus (MAINKA, 2012; CASIMIRO \& SILVEIRA, 2012).

O funcionamento da administração colonial na América Portuguesa demonstra a forma complexa e contraditória que a sociedade colonial se constituiu. O planejamento nem sempre gerou bons resultados, e ao final a prática prevaleceu durante as ações na colônia, mesmo contrariando os regimentos oficiais. A nova historiografia tem buscado analisar como os agentes administrativos fizeram funcionar todo esse processo, levando em consideração a precariedade dos recursos e a dissociação estrutural entre os interesses privados e as ações do poder público.

A Companhia de Jesus e Tomé de Souza chegaram à América Portuguesa no mesmo ano, em 1549. O governador possuía objetivos políticos e econômicos à sua vinda, os jesuítas possuíam objetivos - principalmente -religiosos na nova colônia portuguesa. Casimiro \& Silveira (2012) reiteram que enquanto a Europa via na colonização uma nova forma para alargar e expandir o mercado, a Igreja enxergava a possibilidade de catequizar, propagar a fé e conquistar novos adeptos.

Apesar da Europa, no período, vivenciar um momento de grandes mudanças ideológicas, boa parte da cultura portuguesa permaneceu sob a visão teológica, se mantendo firme as ideologias que regiam a sociedade. Os padres que vieram para a colônia trouxeram consigo esperanças de um bom resultado. Dessa forma, os 


\section{HISTÓRIA \\ MUNDO LUSO BRASILEIRO: RELAÇÕES DE PODER E RELIGIÃO}

jesuítas deveriam desempenhar diferentes funções, como a de serem missionários, confessores e - especialmente - educadores; “[...] esta última função eles desempenharam com tamanho zelo que acabou por se constituir na principal atividade da Ordem Inaciana" (CASIMIRO \& SILVEIRA, 2012, p. 205).

A concepção dos jesuítas sobre a educação estruturou e norteou sua permanência na colônia. Para os padres, a mesma se apresentava como possibilidade de alcançar a virtude. Possuíam como objetivo formar indivíduos além da escrita e leitura, mas oferecer uma formação moral dos sujeitos. A educação e a instrução caminhavam juntas (COSTA \& MEN, 2012); e, por isso, deveriam coexistir com todas as demais áreas da vida.

Pedagogia e escolas jesuíticas na América Portuguesa

Nas origens do sistema pedagógico da Companhia de Jesus, o ciclo da formação jesuítica finalizava com os estudos teológicos, pois assim teria "[...] o estudante acesso ao pleno sentido do homem que ele deve ser e que ele deve fazer nascer, no seio da sociedade" (PAIVA, 1981, p. 03). A Companhia estabeleceu dois tipos diferentes de colégios: um privado - exclusivamente para a formação de futuros jesuítas, e outro público - para a formação dos jovens em geral. Entretanto, tal divisão não apresentava-se tão rigorosamente a ponto de não permitir a existência de colégios onde estudassem tanto os seminaristas quanto a comunidade externa. Os menos favorecidos tinham a oportunidade de encontrar nesses colégios de forma gratuita o que teriam que pagar em outro; e, dos estudos colheriam bons frutos os quais poderiam retribuir ao serviço de Deus (RODRIGUES, 1931a).

$\mathrm{Na}$ Companhia de Jesus parecia ser recorrente incentivar e cultivar competições entre os estudantes. Para os padres essa prática precisava acontecer de forma saudável e sem humilhações. Não havia o objetivo de ressaltar o fracasso do perdedor, mas demonstrar honestamente a honra daqueles que se esforçaram a realizar um trabalho brilhante e digno de reconhecimento.

De um modo particular porém se despertava este nobre sentimento pelos prêmios, com que se galardoavam esforços de maior diligência REHR | Dourados, MS | v. 13 | n. 25 | p. 35-54 | Jan. / Jun. 2019 


\section{HISTÓRIA \\ MUNDO LUSO BRASILEIRO: RELAÇÕES DE PODER E RELIGIÃO}

e êxitos mais brilhantes. Os prêmios ou se davam nas aulas pelo professor ou com mais solenidade perante luzido ajuntamento de personagens (RODRIGUES, 1931a, p. 446).

Preservava-se, ainda, o teatro como estratégia pedagógica. Estruturava-se uma minuciosa escolha e alta dedicação em peças com fundos morais. Não só o teatro, mas todas as esferas da educação estudantil passaram a ter fundo moral, virtude essa que para os membros da Companhia seria indispensável a fim de que se realizasse um trabalho com dedicação.

Cumpria-se deste modo cuidadosamente a regra do santo fundador, que nas suas Constituições preceituava que $<<0$ fim que se procurava nos estudos da Companhia, era o proveito das almas próprias e das do próximo >>. Segundo esta norma, nas primeiras regras que se exararam para dirigir a educação da juventude, se inculcavam aos estudantes os exercícios de piedade e freqüência de sacramentos, e se recomendava aos professores tivessem continuamente a mira naquele fim espiritual, a que deviam tender (RODRIGUES, 1931a, p. 450).

Todo o funcionamento das instituições deveriam ser monitorados. O monitoramento e as aulas eram divididas em decúrias, e à frente de cada repartição colocava-se um monitor a fim de se vigiar o comportamento de todos $\mathrm{e}$ responsabilizar-se em avisar o mestre caso alguma infração ocorresse por meio dos alunos. Os religiosos acreditavam que o método de monitoramento seria uma das melhores formas de garantir o sucesso e a disciplina escolar.

Dom João III foi o primeiro integrante da realeza a financiar e dar segurança aos padres em território luso. Podemos considerar, então, que a Companhia foi apoiada e desenvolveu-se com tamanha eficácia devido à gentileza e empenho do monarca português. Os colégios jesuíticos, principalmente os do Novo Mundo, pregavam não objetivar fins mercantis, o que não permitia que se mantivessem sozinhos. Sendo assim, principalmente na colônia, a Ordem inaciana sobrevivia com a caridade dos fiéis e generosidade dos benfeitores; tanto que os colégios admitiam gratuitamente a permanência de seus alunos em tais locais.

De acordo com Leite (1965), uma das preocupações do Rei Dom Sebastião sucessor de Dom João III -, eram as "gentes bárbaras". Este termo foi utilizado para se referir aos índios e mamelucos. Um dos instrumentos de combate a esta ofensiva 


\section{HISTÓRIA \\ MUNDO LUSO BRASILEIRO: RELAÇÕES DE PODER E RELIGIÃO}

era realizar um processo de aculturação do cristianismo que estavam objetivadas pela fé evangelizadora e pela escolarização das primeiras letras nas Casas de Bê-ábá. Para que isso fosse possível, a Ordem necessitava maiores financiamentos.

As rendas principais, que podiam manter os colégios da Companhia, eram as que lhes provinham de bens eclesiásticos. Desde o ano de 1546 se foram anexando a cada colégio antigos mosteiros e igrejas, de cujos rendimentos auferiam os religiosos, segundo os termos de anexação feita por autoridade legítima, os meios de subsistência. Desta maneira, sem prejuízo dos bens nacionais, e até sem diminuição de fortunas particulares, se provia comodamente à grande obra da instrução do povo português (RODRIGUES, 1931a, p. 455).

Desde a formação da Ordem fica instituído que a renda dos colégios seriam destinadas à Igreja e dentro desta permaneceria. A única possibilidade de transferência de renda seria a permuta financeira entre essas Casas. Os colégios da jesuítas foram conhecidos, mais tarde, não por apenas admitir sujeitos da Ordem, mas também estudantes que não tivessem por vontade própria integrarem a Companhia. Os que matriculavam-se na intenção de seguir o caminho jesuítico deveriam sujeitar-se a todas as regras impostas e estabelecidas; os que entravam sem essas intenções deveriam respeitá-las, mas já sabiam que não teriam tanto rigor a segui-las.

Diferente das preocupações vigentes dos colégios lusos, com a chegada dos jesuítas na colônia brasileira, houve preocupação em catequizar. Isso exigia dos padres muito mais do que apenas força de vontade. Os inacianos, no ápice de sua religiosidade e fé, acreditavam que as atividades não lhes custariam muito. Entretanto, ao abrigar uma grande quantidade de crianças na região da América Portuguesa, o preço começou a elevar-se. A insistência em catequizar os pequenos se deu devido à grande resistência cultural por parte dos índios adultos (BITTAR \& FERREIRA JR., 2007).

Para continuar com o projeto de catequização e educação, os padres jesuítas deveriam encontrar formas para sobreviver, uma vez que a Companhia de Jesus instituiu as Casas de Bê-á-bá como necessidade primordial no processo de colonização. Os religiosos defendiam que só seria possível os índios serem catequizados se soubessem, ao menos, o "bê-á-bá". 


\section{HISTOORIA \\ MUNDO LUSO BRASILEIRO: RELAÇÕES DE PODER E RELIGIÃO}

No entendimento dos padres, para que fosse possível o funcionamento das casas e dos colégios, seria necessário o pleno atendimento das necessidades básicas, como: as vestimentas, os calçados e, principalmente, a comida. Os jesuítas faziam votos de pobreza, e isto se tornou social - ou seja, todos do grupo deveriam dividir, compartilhar e manter atos comunitários.

As doações obtidas pela Companhia não eram suficientes para a sobrevivência dos grupos e instituições. Então, liderados pelo padre Manuel da Nóbrega, os jesuítas viram como forma de subsistência a criação de gado nas terras cedidas a eles pela Coroa Portuguesa. O couro do animal servia como matéria prima e o leite, queijo e carne para alimentar as crianças que viviam nos colégios (CASIMIRO \& SILVEIRA, 2012).

Padre Nóbrega, escreve em 1556 - ao padre Miguel de Torres, e faz uma síntese da origem e necessidades a serem atendidas pelas Casas de Bê-á-bá na colônia:

Achegamos à Baya onde começamos de exercitar-se com ho gentio e com os christãos, vivendo de esmolas. Ho anno logo seguinte vierão outros quatros padres e, com estes, sete ou oito meninos órfãos da casa de Lixboa, com huma precuração do Padre Pedro Domenico, que deles tinha cuidado, pera eu poder fazer casas e comfrarias da maneira que em Lixboa se fizeram, e com eles não veo nenhum aviso, mas estes vinhão encarregados aos Padres. Vendo eu isto, determinei-me com os demais Padres e Irmãos que aqui nos achamos parecendo-nos ser causa de que a Companhia se encarregava, a fazer-Ihes casa; e pedi terras ao Governador [Tomé de Souza], ouve-Ihes alguns escravos d'El-Rei e humas vaquas pera criação, determinando, com aquelles que vierão, manter outros órfãos da terra, que avia muitos perdidos e faltos de criação e doutrina, e dos filhos do gentio quantos se podessem manter na casa (NÓBREGA, 1955, p. 209).

Os primeiros "alunos" destas casas de bê-á-bá foram "matriculados" em Salvador, no ano de 1549, para serem instruídos por aquele que seria o primeiro mestre-escola do Brasil: Vicente Rijo. As crianças que estudavam nas, ditas, "escolas" "[...] eram bilíngues, pois falavam o tupi da mãe e entendiam o português do pai", além disso, Rijo não "[...] ensinava apenas às crianças: a sua 'escola de ler e escrever' também era frequentada pelos índios adultos" (BITTAR \& FERREIRA JÚNIOR, 2007). 


\section{HISTÓRIA}

\section{MUNDO LUSO BRASILEIRO: RELAÇÕES DE PODER E RELIGIÃO}

As primeiras Casas de Bê-á-bá eram bastante rústicas e simples. Possuíam instalações precárias que estavam de acordo com a vida dos primeiros portugueses habitantes da colônia portuguesa. Nóbrega, em setembro de 1557, envia correspondência ao Padre Miguel de Torres fazendo uma descrição de como uma das casas se mantinha organizada:

[...] fizemos nela as seguintes repartições, scilicet, hum estudo e hum dormitorio e hum corredor, e huma sacristia por rezão que outra casa que está no mesmo andar e da mesma grandura nos serve de ygreja por nunca despois que estamos nesta terra sermos poderosos pera a fazer, o que foy de sempre dezermos missas em nossas casas. Neste dormitorio dorminos todos asi Padres como Irmãos asaz apertados. Fizemos huma cozinha e hum refeitorio e huma despensa que serve a nós e aos moços. Da outra parte está outro lan.o de casas da mesma compridão, e huma delas dormem os moços, em outra se lee gramatica, em outra se ensina a ler e escrever; todas estas casas asy humas como outras são térreas; tudo isto está em quadra. O chão que fica entre nós e os moços não hé bastante pera que repartindo-sse eles e nós fiquemos agasalhados, mayormente se nele lhes ouvesem de fazer refitorio, despensa e cozinha como será necessario. Todas as mais casas necessarias a huma communidade nos faltão a nós e a eles, como são humas necessarias, casa d'agua e de lenha, e outras desta maneira que quá são muy necessarias, e no sytio não há maneira pera se fazer, e soubretudo não lhe fica servintia pera a fonte e cousas necessarias ultra de não terem ygreja senão a nossa (NÓBREGA, 1955, p. 263-264).

Bittar e Ferreira Junior (2007, p. 39) descrevem a fala de Manuel da Nóbrega, a qual o padre queixa-se e relata ser impossível sustentar tal empreendimento da fé com base apenas na mendicância, "[...] pois entendia que a questão da base material de sustentação das casas seria um fator fundamental, em larga medida, para que a iniciativa catequética lograsse êxito". Além disso, Nóbrega afirmava veemente que seria pouco provável a manutenção das casas educativas, assim chamadas "Casa de Bê-á-Bá" sem o compromisso do braço escravo.

Uma das primeiras fundações foi a Casa de Salvador. Essa iniciativa deu impulso para a criação de muitas outras, como por exemplo, a de Piratininga. Com o processo de fortalecimento das Casas, o Padre Nóbrega descreveu o funcionamento das mesmas e ressaltava a inviabilidade em continuarem a depender de esmolas dos colonos: 


\section{HISTÓRIA}

\section{MUNDO LUSO BRASILEIRO: RELAÇÕES DE PODER E RELIGIÃO}

Ha mantença da casa, a principal hé o trabalho de hum Irmão ferreiro [Mateus Nogueira], que, por consertar as ferramentas dos índios, lhe dão de seus mantimentos, e hé a boa indústria de hum homen leigo que, com tres ou quatro escravos da casa e outros tantos seus, fas mantimentos, criação, com que mantem a casa, e com algumas esmolas que alguns fazem à casa, e com a esmola que El-Rei dá. Tem tãobem esta casa humas poucas de vacas, as quais, por nossa comtemplação, se derão aos meninos quando estavão em São Vicente, e do leite dellas se mantem a casa. A casa de S. Vicente se fiquou pêra se viver de esmolas, os que se nella podessem sustentar, que serão dous ou tres somente (NÓBREGA, 1955, p. 211).

As discussões internas acerca dessa perspectiva eram bem distintas. Dependia do jesuíta e onde estava localizada sua instalação - ao considerar o caráter regimental, por isso essas demandas acabaram sendo levadas à análise em Roma. Com isso, o Papa concedeu aos jesuítas o direito de trabalharem e conquistarem riquezas terrenas, pois só assim conseguiriam a sobrevivência no Novo Mundo. O trabalho se tratava, e se tornava, de cunho essencial, de grandes necessidades econômicas.

Os jesuítas passam a ser conhecidos na historiografia como missionários fazendeiros, pois além de terem como objetivo alcançar a espiritualidade da população residente no período, teriam também que administrar os negócios materiais porque financiariam estas atividades catequético educativas (ASSUNÇÃO, 2014).

O entendimento de infância encontrados em terras brasileiras eram completamente diferentes daqueles vivenciados na Europa; nesse sentido, os clérigos tiveram que se adaptar à nova realidade. Para maior agilidade de uma "adequação" do comportamento das crianças nativas aos moldes portugueses, em 1550, são enviados órfãos às terras brasílicas. A vivência coletiva dessas crianças nas escolas traria maior facilidade na vivência da língua nativa, o tupi, e ajudariam os jesuítas na catequização (CASIMIRO \& SILVEIRA, 2012). A educação dos jesuítas era baseada na catequização, instruindo de forma complementar a leitura, a escrita e matemática básica.

Em boa parte das aldeias da costa, por onde passavam, os padres inacianos estabeleciam 'pequenos seminários'. Eram as chamadas 


\title{
HISTÓRIA \\ MUNDO LUSO BRASILEIRO: RELAÇÕES DE PODER E RELIGIÃO
}

casas de bê-á-bá, espaços onde ministravam às crianças indígenas o ensino da doutrina e das primeiras letras (CASIMIRO \& SILVEIRA, 2012, p. 218).

A disciplina educacional apresentava-se rígida, assim como os professores que exigiam o mesmo dos alunos, com uso de castigos corporais e penas caso não houvesse total submissão. No entendimento de Costa \& Men (2012), Inácio de Loyola se preocupou em suavizar os castigos dos discentes, transformando - por vezes - uma penalização corporal em penas morais. Sobre a penalização de cunho moral, vale a pena destacar um exemplo:

\begin{abstract}
Mandou-se a um menino buscar umas limas doces. O menino foi, mas escondeu algumas no quintal, José de Anchieta, que estava sentado na escola com o Padre Vicente Rodrigues, chamou então outro menino estudante, Domingo Garcia (mais tarde Padre e grande sertanista) e disse-lhe que fosse ao quintal e Ihe trouxesse as limas que acharia escondidas em certo buraco, que lhe indicou. Chegadas as limas, Anchieta entregou-as ao menino que as escondera, dizendo-lhe: Toma-as, são para ti, mas não furtes! O menino arrebentou em lágrimas e não as quis comer de vergonha. A lição fora expressiva e humana (LEITE, 1938, p.92).
\end{abstract}

É com base nessa moralidade que estruturava-se a educação religiosa. Ao escrever para Inácio de Loyola, o jesuíta Padre Anchieta, disserta sobre o ensino e a condução pedagógica nas casas:

Estes, entre os quais vivemos [índios de Piratininga], entregam-nos
de boa vontade os filhos para serem ensinados, os quais depois,
sucedendo a seus pais, poderão constituir num povo agradável a
Cristo. Na Escola, muito bem ensinados pelo Mestre António
Rodrigues, encontram-se 15 já baptizados e outros, em maior
número, ainda catecúmenos. Os quais, depois de rezarem de
manhas ladainhas em coro na lgreja, a seguir à lição, e de cantarem
à tarde a Salve Rainha, são mandados para suas casa; e todas as
sextas-feiras fazem prociss.es com grande devoção, disciplinando-se
até ao sangue (ANCHIETA, 1957, p. 106).

Essas Casas funcionaram fornecendo os requisitos básicos de aprendizagem como o ler e o escrever, mas a sua estrutura funcionava de forma precária porque necessitavam de muitos requisitos indispensáveis para um bom andamento do percurso. Essas Casas constituíram na primeira experiência pedagógica praticada pela Companhia de Jesus nas terras brasílicas. As crianças e os clérigos dormiam 


\section{HISTÓRIA \\ MUNDO LUSO BRASILEIRO: RELAÇÕES DE PODER E RELIGIÃO}

juntos porque não havia, sequer, condições para divisões de dormitórios. A alimentação se provinha por meio do trabalho escravo e das vacas cultivadas pelos padres nos espaços a eles cedidos.

Bitar e Ferreira Junior (2007) discutem uma similaridade entre as Casas de Bê-á-bá e a educação provida pela cultura hebraica, pois construíam sala de aula aos fundos da Igreja, assim como nas sinagogas judaicas. Dessa forma, recuperavam, indiretamente, elementos de uma tradição que até então era considerada proibida e errônea pelos próprios cristãos ibéricos.

Considerações finais

A presença dos jesuítas no período colonial é um fato marcadamente histórico. A condução da Companhia de Jesus foi um diferencial para a estruturação da educação nas terras brasílicas. Embora outras Ordens transitassem na colônia, foi a Companhia de Jesus que - por meio da Coroa Portuguesa - auxiliaram nas questões educativas, fosse pelo empreendimento de colégios ou pelas Casas de Bêá-bá. Essas Casas apresentavam duas principais funções: a conversão dos chamados gentios e principais bases para os colégios jesuíticos no Brasil colônia.

A partir dessa narrativa, podemos perceber o impacto da catequese, e da instrução, na educação jesuítica na América Portuguesa do século XVI. As Casas de Bê-á-bá se transformaram em uma das primeiras disseminadoras de valores cristãos ocidentais de caráter efetivo no Brasil colonial. Para alcançar esse objetivo, os padres jesuítas utilizaram uma pedagogia fundamentada nos seguintes elementos: bilinguismo (português e tupi), ensino da memorização, catecismo com os dogmas cristãos, ridicularização dos mitos indígenas e o ensino de música e teatro.

As Casas de Bê-á-bá simbolizaram um momento distinto onde os padres deslocaram o centro do interesse catequético do indígena adulto para a criança, que acreditavam que ensinando a ideologia aos pequenos esta pudesse conquistar o coração da família. Não somente isso, mas também defendiam a convicção de que passados a religiosidade cristã às crianças desde pequenas, anulariam - ou diminuiriam - o contato com a cultura de seus pais, condenando seus valores 


\section{HISTÓRIA \\ MUNDO LUSO BRASILEIRO: RELAÇÕES DE PODER E RELIGIÃO}

culturais. Essas Casas se transformaram, juntamente com as Igrejas, nas primeiras instituições do Brasil colonial que tinham como princípio, para além de catequizar, atribuir aos gentios valores da civilização ocidental cristã.

\section{REFERÊNCIAS BIBLIOGRÁFICAS}

ANCHIETA, José de. Carta ao Padre Inácio de Loyola, Roma (S.o Paulo de Piratininga, 1 de setembro de 1554). In: LEITE, Serafim, S.J. Cartas dos primeiros jesuítas do Brasil. Coimbra: Tipografia da Atlantida, 1957, p. 101-118. (v. 2).

ASSUNÇÃO, Paulo de. Os Colégios Jesuíticos e a Produção e Circulação do saber no Império Colonial Português. In: RIBAS, Maria Aparecida de Araújo Barreto; SKALINSKI JUNIOR, Oriomar; TOLEDO, Cézar de Alencar Arnaut. (Orgs.). Origens da Educação Escolar no Brasil Colonial - Volume II. Maringá: EDUEM, 2014.

BITTAR, Marisa. FERREIRA Jr, Amarilio. Casas de bê-á-bá e colégios jesuíticos no Brasil do século 16. In: FERREIRA Jr, Amarilio. Instituto Nacional de Estudos e Pesquisas Educacionais Anísio Teixeira. v. 1, n. 1. Educação Jesuítica no Mundo Colonial Ibérico (1549-1768) Brasilia: O Instituto, 2007.

CASIMIRO, Ana Palmira Bittencourt Santos. SILVEIRA, Camila Nunes Duarte. Notas sobre a ação pedagógica da Companhia de Jesus no Brasil de 1549 a 1599. In: TOLEDO, Cézar de Alencar Arnaut, RIBAS, Maria Aparecida de Araújo Barreto, SKALINSKI Jr, Oriomar (organizadores). Origens da educação escolar no Brasil Colonial. Vol. I Maringá: Eduem, 2012.

CONSTITUIÇÕES da Companhia de Jesus e NORMAS Complementares. São Paulo: Loyola, 1997.

COSTA, Célio Juvenal. MEN, Priscila Kelly Cantos. Características da educação nos colégios jesuíticos em Portugal e no Brasil no século XVI. In: TOLEDO, Cézar de Alencar Arnaut, RIBAS, Maria Aparecida de Araújo Barreto, SKALINSKI Jr, Oriomar (organizadores). Origens da educação escolar no Brasil Colonial. Vol. I Maringá: Eduem, 2012.

FRANCA, Leonel. O método pedagógico dos jesuítas. Rio de Janeiro: Agir, 1952.

GINZBURG, Carlo. Mitos, emblemas, sinais: morfologia e história. In: GINZBURG, Carlo. Sinais: Raízes de um paradigma indiciário. São Paulo: Companhia das Letras, 1989.

INÁCIO DE LOYOLA, Santo. Exercícios Espirituais. 7a ed. São Paulo: Loyola, 2002. 


\section{HISTÓRIA \\ MUNDO LUSO BRASILEIRO: RELAÇÕES DE PODER E RELIGIÃO}

KOSELLECK, Reinhart. Uma história dos conceitos: problemas teóricos e práticos. Estudos Históricos. Rio de Janeiro, vol. 5, n. 10, 1992, p. 134-146.

LEITE, Serafim (S.J.). História da Companhia de Jesus no Brasil. T.7. Lisboa: Portugália; Rio de Janeiro: INL, 1938-1949.

MAINKA, Peter Johann. O início da colonização do Brasil no contexto da Expansão marítima portuguesa (1415-1549). In: TOLEDO, Cézar de Alencar Arnaut, RIBAS, Maria Aparecida de Araújo Barreto, SKALINSKI Jr, Oriomar (organizadores).

Origens da educação escolar no Brasil Colonial. Vol. I Maringá: Eduem, 2012.

NÓBREGA, Manuel da. Carta ao P. Miguel de Torres, Lisboa (S.o Vicente, maio de 1556). In: LEITE, Serafim, S. J. Cartas do Brasil e mais escritos. Intr. e notas históricas e críticas: Serafim Leite S.I. Coimbra: Universidade de Coimbra, 1955. p. 207-215.

Carta ao P. Miguel de Torres, Lisboa (Baía, 2 de setembro de 1557). In: LEITE, Serafim, S. J. Cartas do Brasil e mais escritos. Intr. e notas históricas e críticas: Serafim Leite S.I. Coimbra: Universidade de Coimbra, 1955. p. 260-276.

PAIVA, José Maria de. Religiosidade e cultura brasileira: séculos XVI-XVII. Maringá: Eduem, 2012.

José Maria de. O Método Pedagógico Jesuítico: uma análise do Ratio Studiorum. Viçosa - Minas Gerais: Oficinas Gráficas da imprensa Universitária da Universidade Federal de Viçosa. 1981.

RATIO atque Institutio STUDIORUM - Organização e plano de estudos da Companhia de Jesus. In: FRANCA, Leonel, $\mathbf{O}$ método pedagógico dos jesuítas. Rio de Janeiro: Agir, 1952.

RODRIGUES, Francisco. A formação intellectual do jesuíta - leis e factos. Porto: Magalhães \& Moniz, 1917.

RODRIGUES, Francisco. História da Companhia de Jesus na Assistência de Portugal. Tomo I - Volume I. Pôrto: Apostolado da Imprensa, 1931a.

Francisco. História da Companhia de Jesus na Assistência de

Portugal. Tômo II - Volume I. Pôrto: Apostolado da Imprensa, 1931b.

WOORTMANN, K. Religião e Ciência no Renascimento. Brasílias: UNB, 1997. 